\title{
Citizen Seismology Without Seismologists? Lessons Learned From Mayotte Leading to Improved Collaboration
}

\author{
Laure Fallou $^{1 *}$, Rémy Bossu ${ }^{1,2}$, Matthieu Landès ${ }^{1}$, Julien Roch ${ }^{1}$, Frédéric Roussel ${ }^{1}$, \\ Robert Steed ${ }^{1}$ and Sylvain Julien-Laferrière ${ }^{1}$
}

${ }^{1}$ EMSC (Euro-Mediterranean Seismological Centre), Arpajon, France, ${ }^{2}$ CEA, DAM, DIF, Arpajon, France

\section{OPEN ACCESS}

Edited by:

Tarla Rai Peterson,

The University of Texas at El Paso,

United States

Reviewed by:

Wei Peng,

National Taiwan Normal

University, Taiwan

György Hetényi,

University of Lausanne, Switzerland

*Correspondence:

Laure Fallou

fallou@emsc-csem.org

Specialty section:

This article was submitted to

Science and Environmental

Communication,

a section of the journa

Frontiers in Communication

Received: 07 February 2020

Accepted: 16 June 2020

Published: 12 August 2020

Citation:

Fallou L, Bossu R, Landès M, Roch J,

Roussel F, Steed R and

Julien-Laferrière $S$ (2020) Citizen

Seismology Without Seismologists?

Lessons Learned From Mayotte

Leading to Improved Collaboration.

Front. Commun. 5:49.

doi: 10.3389/fcomm.2020.00049
Starting the 10th May 2018, a series of earthquakes has hit Mayotte, a French island in the Indian Ocean. Facing a lack of seismic data, scientific information and communication from the authorities, the inhabitants took advantage of social media to develop, on their own, a citizen seismology group, composed of more than 10,000 people. Due to a particular cultural context, this was carried out mainly without the seismologist community. While some citizens did share seismological information (and eventually volcanology information when it was discovered that the earthquakes were caused by a new-born, undersea volcano), the lack of seismologists in the group also lead to the emergence of misinformation and even conspiracy theories. This mistrusting atmosphere had negative consequences for the way various seismological organizations were perceived, including LastQuake, a crowdsource-based earthquake information app which allows eyewitnesses to share information about earthquakes they felt, combined with seismic data. However, due to the lack of seismic data for these earthquakes, some were not displayed in the app. This lack of information and understanding of how the system functioned led to additional mistrust toward this citizen seismology tool. This paper combines sociological observations with an empirical approach. First, a sociological analysis of this independent citizen science network enables an identification of the reasons for its creation and the pitfalls caused by the absence of collaboration with the scientific community. Then, an empirical case study of the LastQuake system exposes how it has been improved to offer information, while admittedly more incomplete, is nevertheless closer to citizens' needs. It concludes that citizen seismology requires a stronger collaboration between citizens' and scientists' communities in order to be more efficient. It also advocates for scientific communication that takes into account cultural context from the beginning.

Keywords: citizen science, seismology, science communication, crisis communication, misinformation, conspiracy theory, risk culture, social media 


\section{INTRODUCTION}

Within citizen science, seismology holds a special place as earthquakes are not only a fascinating phenomenon, but also a potentially deadly risk. Thus, involving citizens in seismology has been impacting the way it is made and disseminated as a science, and has also contributed to reducing risk (Khan et al., 2018). Citizen seismology is here defined as any project, formalized or not, involving citizens around earthquake related themes, aiming at increasing scientific and risk knowledge, either for the scientific community or the involved citizens.

Citizens have long been an essential part of the way seismology is made. Amateurs and eyewitnesses were relied upon for observations before the development of measuring tools (Ferreira, 2019) and after their introduction, to compensate for a lack of data or to complement it. Indeed, their testimonies have contributed to mapping the effects of earthquakes (Aronova, 2017). However, the way citizens take part in seismology is evolving, especially with the rise of new technologies, including smartphones and new types of seismic sensors.

The spectrum of actors involved in citizen seismology is broadening. While only amateur seismologists or eyewitnesses used to be involved, it tends to grow beyond age and universally, including also children in schools (Liang et al., 2016; Subedi et al., 2020), and entire communities (Calais et al., 2018), implying that prior knowledge and interest levels may be relatively low. Furthermore, new and more independent actors have since appeared in the field. For instance, the Earthquake Network app uses smartphones' accelerometers to detect earthquakes (Finazzi, 2016) and the Euro-Mediterranean Seismological Center (EMSC), with the LastQuake project (Bossu et al., 2011) uses crowdsourcing to detect felt earthquakes and inform the public about them. Operating worldwide, these projects face specific challenges associated with gathering citizen observation.

Starting as passive observers, citizens have become more and more involved. They can now report earthquakes or damages (Wald et al., 2012), help with measurements or computation, learn how to locate earthquakes or take an active role in risk reduction activities (Liang et al., 2017). Recent projects also study the opportunity to engage citizens in order to augment data at little cost, in both Haiti (Calais et al., 2018) and at a global scale (Finazzi, 2016; Bossu et al., 2018). Citizens' attributed role depends on the purpose of the project. If historically it has been a way to improve scientific knowledge about earthquakes, it is now also a way to raise interest about earthquakes within society, increase citizens' understanding of seismic phenomena and contribute to risk reduction (Coen, 2012), thus demonstrating that citizens' interest must be taken into account alongside those of scientists (Scolobig et al., 2015). It also implies the need to reflect on the mutual relationship between citizens and seismologists and how they interact. Mutual trust, as well as communication, is an essential part of citizen science (Aronova, 2017).

In most citizen seismology projects found in the literature, scientists are taking the lead to build and guide them. This does not hold true in the case of Mayotte. In May 2018, this French island located in the Indian Ocean was hit by a series of, at the time, unexplained earthquakes. To date, the swarm has not stopped yet. Seismic data and explanations for the phenomenon were lacking at the beginning of the swarm. In the face of an information vacuum and a high level of mistrust toward the authorities and the scientific community, the population looked for ways to satisfy their informational and emotional needs. Not only did they turn to existing citizen science projects (such as the LastQuake app) but they also created their own citizen seismology network through a Facebook group called STTM, ("Soutien Tremblement de Terre Mayotte"), standing for "Earthquake support Mayotte." In both of these solutions, conversation with seismologists was limited and relevant seismological information was not readily available. This paper reviews how citizen seismology is made when citizens take the lead in a context of an information vacuum. It evaluates how existing citizen seismology projects, such as LastQuake, can evolve to support citizens, meet their information needs, avoid misinformation and rebuild trust. It does so by first describing the Mayotte case study, which includes an analysis of the seismic and cultural context, a description of the Mayotte citizen science project and of its outcomes. It then presents the LastQuake crowdsourced detection system and how a questionnaire was set up to understand the Mayotte users' needs and improve the LastQuake system to better take them into account in the EMSC citizen science project.

\section{MATERIALS AND METHODOLOGY}

This article is based on a two step-methodology. First, we analyse the situation in Mayotte, based on a sociological approach. We focus on citizens' perspective, considering their perception of the events and the related communication. Indeed, not only the risk or the actual communication matter, but also how they are perceived (Wray et al., 2006). Observations of the Facebook group were made from its creation on May 13th 2018 to the end of November 2019, with a specific focus on the first year of the event. Observations were made possible by one of the authors joining the Facebook group as a passive observer, only in the bystander role, paying attention not to modify interactions and thus, not creating bias (Ditchfield and Meredith, 2018) ${ }^{1}$. Interactions between members, shared information, reactions and content evolutions were analyzed qualitatively. This was supplemented by a series of 10 semi-structured interviews (Edwards and Holland, 2013) ${ }^{2}$ with people living in Mayotte, in August 2018. The interviews aimed at getting insights on how citizens in Mayotte experienced the seismic activity and assess their satisfaction level regarding their information needs. Questions targeted citizens' perception of seismological actors and authorities, which were not primarily mentioned by the interview leader in order to identify the perceived legitimate

\footnotetext{
${ }^{1}$ As it is common on Facebook, the group was composed of active members posting content and discussing it, along with more passive one (Bastard et al., 2017), therefore being a passive observer, researcher do not modify the interaction.

${ }^{2}$ Semi-structured interview is a common method of research within social sciences in which the set of questions is open and can evolve depending on what the interviewee says (Edwards and Holland, 2013).
} 


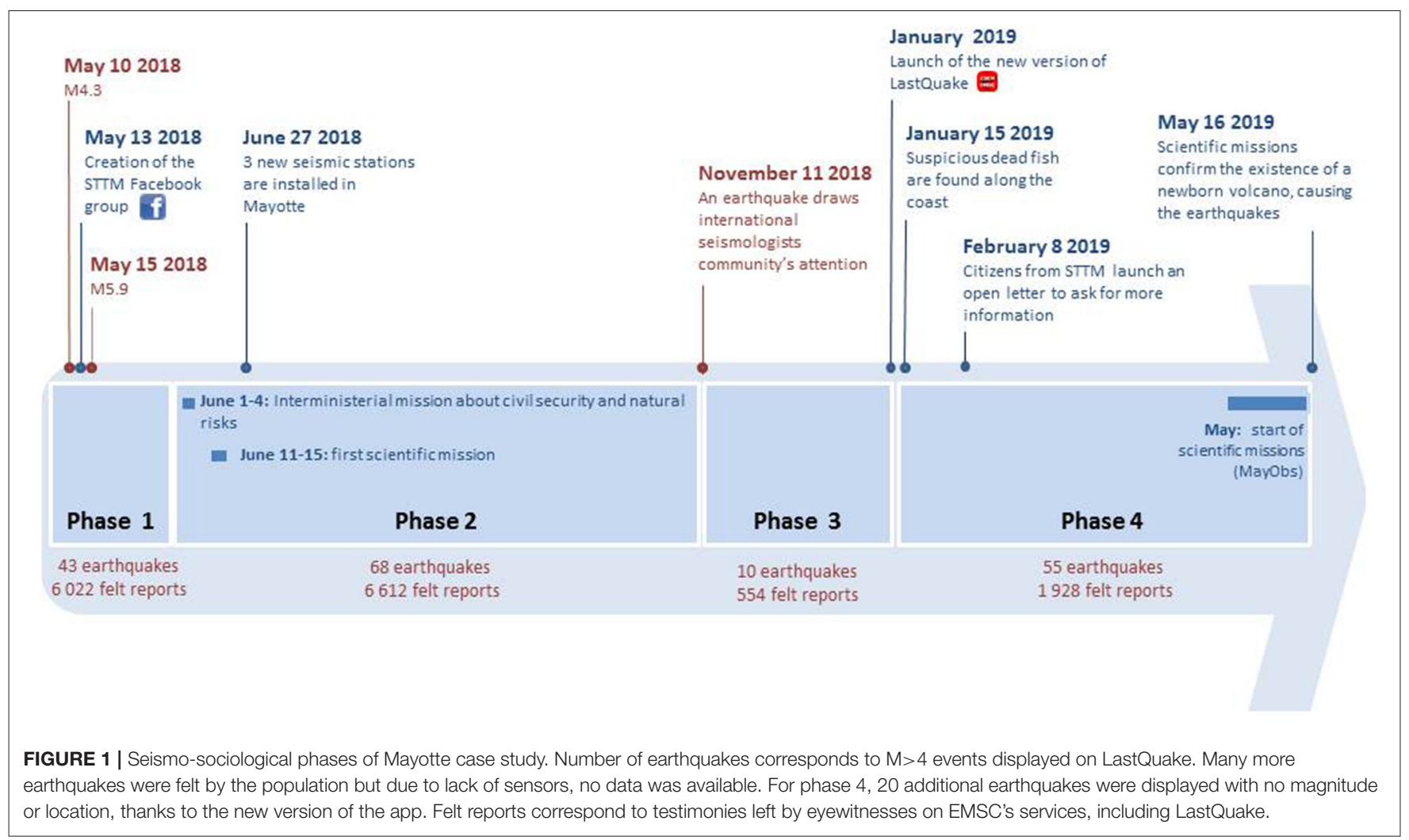

actors. The panel of interviewees is composed of a variety of profile in terms of geographical origin (born in Mayotte or in mainland France), age, gender and social background. It also includes a local journalist and an imam. Results have been pseudonymized; therefore, names have been changed. Consent to the publication of their quotes and indirectly identifiable data was obtained from the participants. All interviews were led in French. Interviewees were canvassed on social media, based on volunteering and on recommendations from other interviewees. This constitutes a bias as most interviewees are therefore globally more educated than the general population of Mayotte. Nevertheless, as part of a qualitative approach the study is not aiming to provide a representative picture of the situation, but to contribute to identifying key aspects of the context.

The second step is empirical. EMSC launched an online questionnaire, targeting its own users in Mayotte in order to better understand what information they need and improve its services. This questionnaire was sent to LastQuake users in Mayotte who had indicated an e-mail address in the app. It was also promoted on Twitter and Facebook. Four hundred and sixtyeight responses were collected between 22 June 2018 and 17 July 2018. Only available in French and requiring an internet access and digital literacy skills, the questionnaire did not aim to collect responses from a representative sample of the population, nor from LastQuake users. It still provides an overview of the anxiety level and information needs among respondents. Following the questionnaire results, LastQuake information system was improved in order to disseminate additional information.

\section{MAYOTTE SEISMIC AND CULTURAL CONTEXT AS AN EXPLANATION FOR INFORMATION NEEDS}

\section{Mayotte Seismic Context and the 2018 Swarm}

The Mayotte sequence can be divided into 4 seismo-sociological phases, which are based on seismic activity, scientific research, communication activities and citizens' reactions (Figure 1).

Phase 1 starts on May 10th 2018 when a M4.3 earthquake was felt in Mayotte during the evening. The event was surprising to the public, as the island is known for having only moderate seismicity. The International Seismological Center (ISC) catalog lists 22 earthquakes with a magnitude $<4$ between 1964 and 2010, within a radius of $300 \mathrm{~km}$ around the island (Figure 2) (International Seismological Centre, 2020). This May 10th event was followed by high seismic activity with between 10 and 30 felt earthquakes per day during the following few weeks (Lemoine et al., 2019). On May 15, the strongest earthquake ever recorded in the region (M5.8) hit the island (Figure 3).

The earthquakes were found to be mostly located about $50 \mathrm{~km}$ east of the island. Many happened at night, waking up citizens, increasing their anxiety level. During the 21 first days of phase 1, EMSC displayed $43 \mathrm{M}>4$ earthquakes on LastQuake. A month after the beginning of the swarm, 1,400 earthquakes had been detected by local seismic networks, 140 with $M>4$ and more than $20 \mathrm{M}>5$ (Lemoine et al., 2019). Some dwellings have been weakened (cracks and fractures could be observed), 


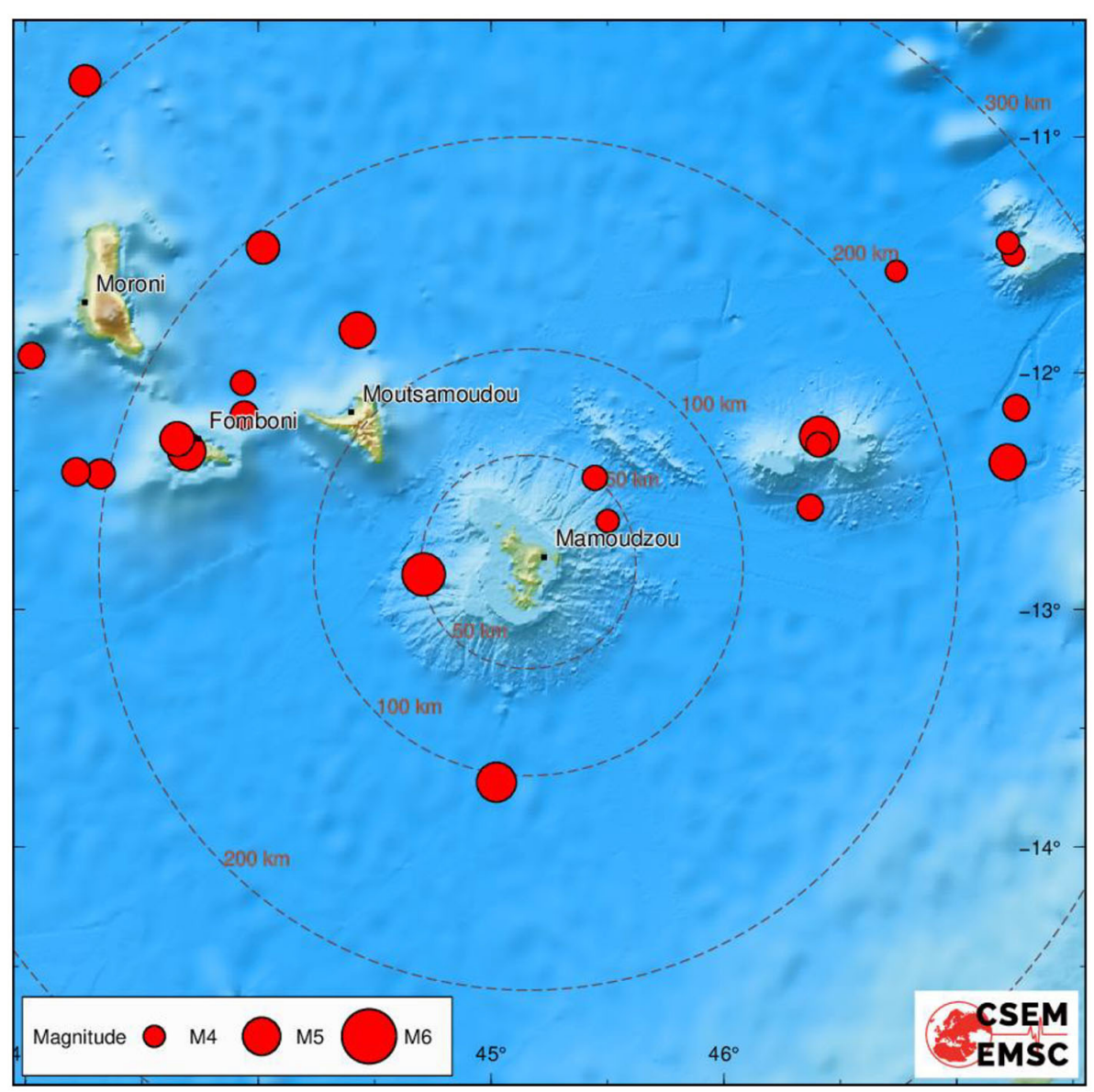

FIGURE 2 | Historic seismicity map near the Mayotte island using the ISC catalog for $M>=4$ earthquakes (1964-2010). Largest event reaches magnitude 5.3.

yet, no casualties have been reported. Due to the lack of seismic sensors in the region, the surge of moderate-size earthquakes was left unexplained initially and many small earthquakes were not detected at all. This intense seismic activity left everyone, scientists, authorities and the population, puzzled.

Phase 2 runs from beginning of June to November 11. During this period, seismic activity continued but at a lower rate. LastQuake was able to display $68 \mathrm{M}>4$ earthquakes in the app during this phase. Seismologists and authorities set up an interministerial mission ${ }^{3}$ to ensure that a reliable organization and logistical means would be operational in the event of a worsening of the seismic crisis. It was complemented by a scientific mission in order to explain the phenomenon. However, many citizens' questions remained unanswered. Indeed, despite the installation of three new seismic stations, data was often lacking on felt earthquakes and scientists needed time to conduct research. This was not well-understood by citizens.

On November 11, the Mayotte case started to draw the attention of scientists in international communities, starting

\footnotetext{
${ }^{3}$ https://lalere.francetvinfo.fr/mayotte/mission-gouvernementale- seismes- estattendue-ce-vendredi-594683.html
}

phase 3 of this analysis. On that day, global networks registered low frequency signals, which could correspond to volcanic tremor that is likely associated with rising magma (Lemoine et al., 2019; Cesca et al., 2020). This raised the interest of the global geoscientist community along with many questions among citizens who still perceived scientific and institutional communication as insufficient.

Finally, phase 4 started in January 2019 and ended in May 2019. It marks a turning point in the case study, not because of the seismic activity but rather due to specific efforts in communication activities toward the public. Messages about the ongoing situation, research activities and safety measures to take were regularly spread on traditional and social media. Research also made important progress, scientists discovered that the cause of this active earthquake swarm is a new-born submarine volcano located $\sim 50 \mathrm{~km}$ from the island (Lemoine et al., 2019; Cesca et al., 2020).

At the time of this paper, the swarm has yet to stop and earthquakes are still being detected and felt by citizens. For instance, in March 2020, seven earthquakes were detected (between M3 and M3.4), including two that were felt by the population. 


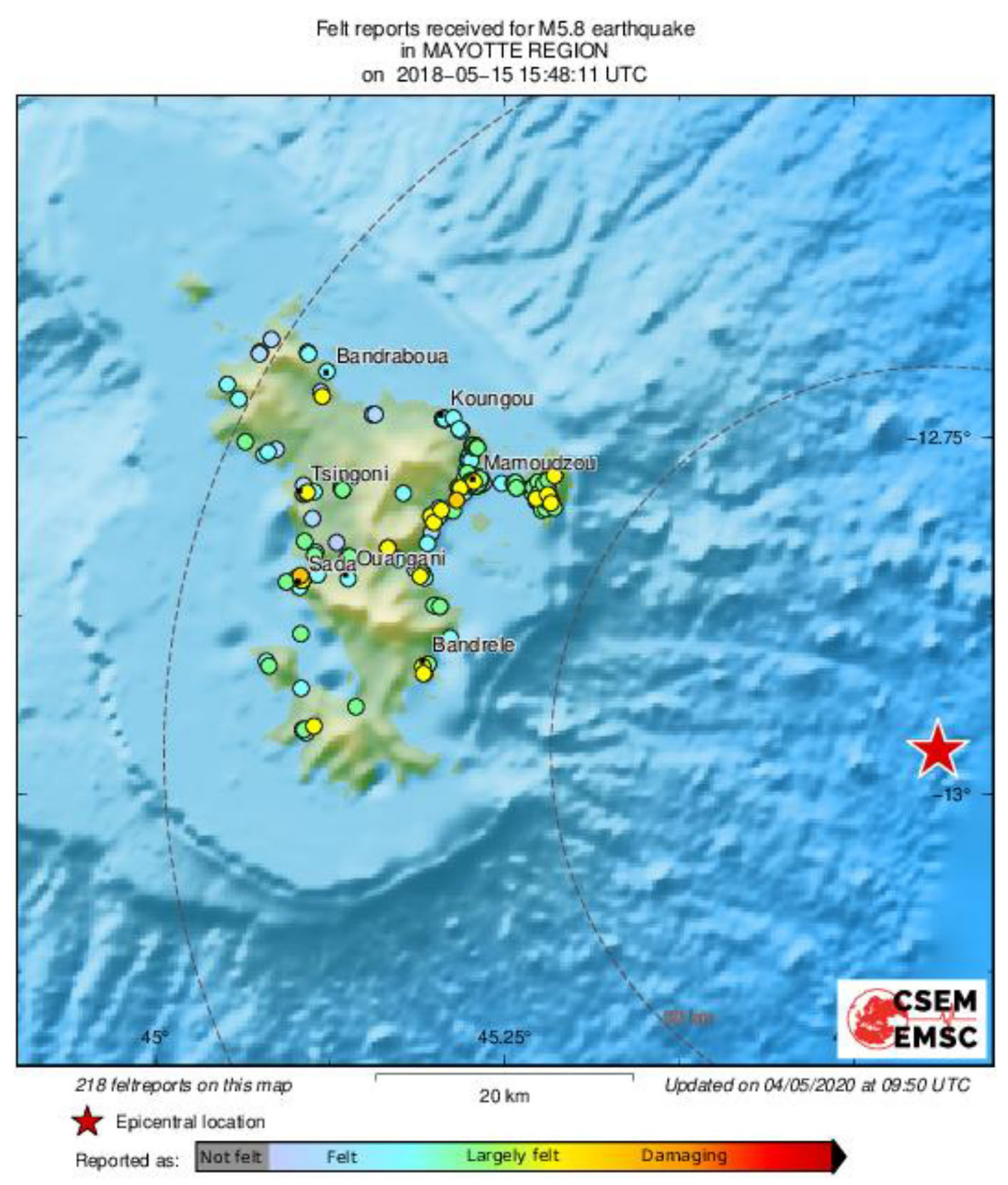

FIGURE 3 | Felt map for the M5.8 earthquake (2018-05-21). Each dot represents a felt report collected by EMSC, color corresponds to the felt shaking intensity reported by citizens.

\section{Mayotte Socio-Cultural Context}

In addition to the unusual seismic activity, cultural factors and context must also be taken into account to understand the full situation in Mayotte (Fallou and Bossu, 2019). The island, inhabited by more than 256,000 people (INSEE, 2017), has a very particular cultural setting despite being part of the French territory (Dauphin and Thibault, 2011). The population suffers more from poverty and illiteracy than on mainland: $84 \%$ of the population lives beneath the poverty threshold and in 2000 35\% of men and $40 \%$ of women were considered as illiterate, while it is only $7 \%$ are among French citizens as a whole ${ }^{4}$. Insecurity feeling is at high level. Mayotte is the French department with

\footnotetext{
${ }^{4}$ https://www.nouvelobs.com/rue89/rue89-mayotte/20111020.RUE5109/nonnon-non-mayotte-ce-n-est-pas-la-france.html
}

the highest delinquency rate. The island is particularly in the lead for burglaries, reaching, in 2016, 19.1 burglaries per 1,000 dwellings, compared to 7.1 in metropolitan France (InterStats, 2017). Socio cultural differences also include religion, as $95 \%$ of people in Mayotte are Muslims ${ }^{5}$, compared to $6 \%$ of the general French population ${ }^{6}$, and a significant part of the inhabitants have animist beliefs (Barthès, 2003). Moreover, in 2007, only $63 \%$ of people aged 14 or older were found to be able to speak French, the official language, demonstrating the importance of the two native languages (Shimaore and Kibushi). Lastly, people in Mayotte have an ambivalent relationship with the authorities, due to the administrative history of the island (Mayotte became

\footnotetext{
${ }^{5}$ http://www.outre-mer.gouv.fr/mayotte-culture

${ }^{6} \mathrm{https} / / /$ www.pewforum.org/interactives/muslim-population/
} 
a French department through a local referendum in 2009), the geographical and cultural distance to mainland France. Findings from the interviews show that on the one hand they have strong expectations for the government to take specific measure to improve the socio-economic situation, but on the other hand they have little hope that they will be taken into account. Suspicion and mistrust are therefore high. In Mayotte as in every French department, the prefecture is the institution which represents the State at a local level, and as such, citizens' expectations are centered around it.

Beyond these cultural characteristics, people in Mayotte were also found to have a low risk culture ${ }^{7}$, especially regarding earthquakes. Indeed, citizens were not used to seismic activity. Few had impacted the territory and earthquakes were not perceived as a risk by the inhabitants. Oral tradition can identify damaging earthquakes in 1606, 1679, and 1788 (Hachim, 2004) and the most recent significant earthquake associated with moderate damage, besides the 2018-2019 crisis, occurred in 1993 (Lambert, 1997). During the interviews most people expressed this perceived lack of preparedness, for themselves but also more generally among the population. For instance, Baptiste, a journalist, declared that not only the population but also the emergency services were not ready to face a major catastrophe. Nadine, a teacher who has been on the island for over 15 years also stated "We were not ready. I had never been told about earthquakes in Mayotte. They didn't exist. When we were doing drills with the kids it was for fire or terrorist attacks, but never for earthquakes. [...] And now the problem for the people is to know whether they should risk a burglary or an earthquake" (Nadine, 60 years old, teacher).

Overall, given the seismic history and cultural context, the population, along with the authorities and to a certain extent the scientific community, was unprepared to face such a seismic crisis.

\section{Citizens' Information Needs and Anxiety Level Unsatisfied Information Needs}

According to the interviews and observations on social media, when the first earthquake hit the island, citizens wanted to get a confirmation that what they felt was an earthquake, know the magnitude and location of the earthquake. They also needed to know how to react in case of an earthquake and how to secure their houses. These are common queries when it comes to a large ground shaking event (Wein et al., 2016). As the earthquakes continued, information needs increased to include explanations for the phenomenon, insights on when would be the next one, what was the largest magnitude that could occur, when would the swarm finally stop and an assessment of tsunami risk.

\footnotetext{
${ }^{7}$ Following Cornia et al.'s work, the concept of risk culture is used to explain "how groups and communities share common ways of perceiving risk, common knowledge about how to deal with disaster, common beliefs about who should be blamed for the disaster consequences, common feelings of trust or mistrust towards authorities and similar informative behaviours to be adopted in case of crisis situations" (Cornia et al., 2016).
}

Depending on various cultural factors, explanations were looked for in different rationality spheres (Boudon, 2001) and from different actors as expressed by Lucile, a teacher born in mainland France but who's family in law is from Mayotte: "Personally, I understood that the $\mathrm{BRGM}^{8}$ didn't know what was going on and that they couldn't know it. But here it's different, first people looked for a religious explanation. They though it was God's will. In their reasoning, scientific explanations come after, in second or third position. But in a way, people still had high expectations toward scientists. They really needed an explanation, and they trusted them to bring this explanation quickly. So... they're waiting, especially now that they've come to the island... and they don't understand why nobody has told them anything" (Lucile, 36 years old, teacher).

Lucile's testimony gives insights on the importance of religious beliefs as an explanation for the earthquakes in Mayotte. Comments left on social media confirm this first sphere of explanation for many people in Mayotte. During the first 6 months, after each earthquake, many comments were posted on Facebook, stating that it was another warning, if not punishment, from God. This is consistent with social science research on the role of religious beliefs in popular explanations for seismic activity, including for Muslims (Severn, 2012; Sibley and Bulbulia, 2012; Chester et al., 2013; Stephens et al., 2013). However, in Mayotte, God's will and other religious beliefs appeared to be insufficient to explain earthquakes, especially when the earthquake activity lasted too long to calm the nerves by religious reason alone. According to most testimonies, including Icham's, an influential Imam, most of the citizens in Mayotte initially thought earthquakes were caused by God, or at least divinities, given the strong Muslim and animist cultural background. He stated that he was himself was looking for other explanations: "I've done a lot of research to know better what the Koran says about earthquakes, and I keep on doing my research. It is said in the Quran that the earth will shake and people will get scared. It does not mean it is the end of the world. So... I'm researching also about what everyone says. My role is to find an explanation to calm people down. So, I'm very interested in what seismologists say" (Icham, 57 years old, imam). Thus, both secular and religious people then turned to scientists in order to get an explanation for the phenomenon.

In the first month of the earthquake swarm, the understanding of where, how big, and why earthquakes occurred is very limited due to several reasons. First, a lot of seismic data went missing due to the lack of station coverage. Many earthquakes felt by citizens were thus not recorded and no data was available to identify them from a scientific point of view. Additionally, scientists were unable to understand the nature and cause of the swarm as it was an unusual and rare case (Lemoine et al., 2019; Cesca et al., 2020). Secondly, information expectations about the prediction of earthquakes and the swarm's end were unsatisfied because they were unrealistic. Indeed, to date, no method of prediction (specifying when and where an earthquake will occur) has been scientifically demonstrated and, at first, scientists were

${ }^{8}$ BRGM stands for Bureau of Geological and Mining Research. It is the national French Geological Service. 
not able to explain the nature and causes of the swarm nor indicate when the swarm would end.

Despite the technical and scientific incapacity to provide this information, expectations toward seismologists remained very high among the population. A widespread image of scientists was that of powerful, nearly omniscient scientists who knew everything about earthquakes. On Facebook, many expressed their incredulity facing the lack of explanations from the seismologist community. Jean also stated: "It's unbelievable that they don't know anything. We feel earthquakes and they don't know anything about them. They are not even capable to explain them, but it's their job!" (Jean, 60 years old, policeman).

These unrealistic expectations can be partially explained by the lack of knowledge about seismology's limits. One could argue that it may be a matter of education. Indeed, among highly educated interviewees, some of them understood the limits of seismologists' knowledge such as Lucile quoted above or Joel, an engineer working for the departmental council: "I quickly understood that they wouldn't be able to tell us what was going on... It will take time for them to research this. But of course, I would love to know what's going on. But for the moment I just have to be patient... and hope it will stop soon" (Joel, 47 years old, engineer). However, education and information about these limits may not be sufficient as these expectations were found to be enhanced by anxiety. For instance, Marie, a lawyer originally from Paris stated her own "irrationality," explaining that even though she knew the BRGM could not yet explain the seismic phenomenon she still needed to understand and they expected the seismologists to find an answer. A need that was increased by her anxiety. Such cognitive errors about seismologist work has been found in other case studies (Celsi et al., 2005).

All interviewees reported a perceived lack of communication from both the authorities (especially the prefecture) and the scientific community, particularly concerning why they failed to provide sufficient information. As far as the scientific community is concerned, interviews and observations demonstrate that people in Mayotte hold high expectations on the BRGM, as it is the national institute. Officially, BRGM's role is to monitor and collect geological, geodetic, and geophysical data to prevent natural hazards and to help decision making. Regarding seismic risk, BRGM is in charge of "regular information when earthquakes are felt, characterization of the risk of liquefaction under school buildings and implementation of a "Seismology for schools" program". In France other institutions such as BCSF (Central Bureau of French Seismicity) or IPGP (Paris Institute of Earth Physics) are also partly responsible for seismic information and observation. However, BRGM was quickly identified by the local population as the main interlocutor and became the center of most of the expectations from citizens in Mayotte. Despite this, people also looked for information from additional sources such as the USGS (United States Geological Survey) or EMSC, demonstrating their urgent need for understanding.

Overall, an absence of science communication and risk communication can be identified. Interviewees noted that they would have understood better if the knowledge limits had been

\footnotetext{
${ }^{9}$ https://www.brgm.fr/regions/reseau-regional/mayotte.
}

explained shortly after the first earthquake. Moreover, they expected the communication to be accessible to all, which implies to be done on various channels, including social media, and in all languages, not only French. Some complained that the authorities and scientific institutions didn't understand their needs. Nadine for instance stated: "I called the mayor's office and the prefecture but they didn't give me any information. They just gave me the number for psychologists for help... but that's not what I needed. I needed an explanation!" (Nadine, 60 years old, teacher). Additionally, interviewees also reported a lack of information in the local media, but they attributed it to the general lack of information they felt the BRGM should be responsible for.

During the first phase of Mayotte swarm, citizens" needs were neither sufficiently managed nor satisfied. This had two consequences: it increased anxiety level, which was already high, and it opened up the space for the propagation of misinformation.

\section{An Anxiety Level Raised by a Lack of Information}

Due to the stress and fatigue induced by a large number of earthquakes, combined with little previous experience of seismic activity in the region, anxiety was very high among people. Marie for instance reports that: "At some point, and it's not only me but everyone I know, we were doing everything depending on the earthquakes. We were thinking... "Do I have time to shower?" or "Maybe I should wait before going to the bathroom because there may be another earthquake, it may be too dangerous". And it lasted for weeks" (Marie, 26 years old, lawyer).

Another interviewee also told that he was so anxious that he slept with a machete to break the wall between his bedroom and his daughter's in case of an emergency. Many earthquakes occurred at night, leading people to sleep outside. Baptiste, a journalist for a local newspaper remembers how they made a special edition one night at 4 a.m. "People were sleeping on the streets, the mosques were calling on people to get out, to evacuate the houses... because they were announcing an aftershock after the tremor that had been recorded at more than $[\mathrm{M}] 6^{10 "}$ (Baptiste, 31 years old, journalist).

Anxiety was found to be enhanced by the perceived lack of information. Many testified that not knowing the causes or how long it would last increase their anxiety. This is consistent with previous work demonstrating that information can partially cure anxiety (Saathoff and Everly, 2002). A poignant example of the effect of a lack of information was found in Joel's interview when he stated with strong emotion in his voice, somewhere between distraught and anger: "NOTHING! We had NOTHING, neither from the prefecture, nor from the BRGM, NOTHING. While everyone could see that it was shaking, that at the moment... We were upstairs, between 20 and 30 people, and everyone could see, when we were at work, that it was shaking at the same time... We're not liars! It happened! But there was nothing!” (Joel, 47 years old, engineer).

\footnotetext{
${ }^{10}$ Baptiste talks here about the M5.8. His mention of $\ll \mathrm{M} 6 \gg$ refers to the fact that magnitude estimation can fluctuate after an earthquake, and collective minds can recall higher magnitudes that are then revised.
} 
As a whole, in the Mayotte case, in the first few months of the crisis, citizens suffered from a perceived lack of scientific and crisis related information. These needs were increased by anxiety, which in turn, increased their anxiety, in a vicious circle.

\section{Information Vacuum Increased Misinformation and Mistrust}

While scientific understanding of the Mayotte earthquake swarm was limited, numerous scientifically unsound theories arose. Marc, a retired man who has lived on the island for over 30 years reported: "We've heard everything! There were crazy rumors about a volcano that was going to rise from the sea ${ }^{11}$, secret petroleum drills were causing the earthquakes, and also the cow, buried alive, was moving its head, making the earth shake... But there were no scientific explanations, so people turned to other beliefs" (Marc, 66 years old, retired). Icham also expresses his personal doubts about theories he heard: "Everyone has theories, I personally don't know exactly so I'm waiting to get information. It is said that people looked for evidence of oil and gas drilling. Everyone has their own imagination. Maybe some of them are right and have the right explanations, but I don't believe it. From what I analyzed it's not the cow either. But still, I can't explain" (Icham, 57 years old, imam).

The theories were of different natures. Some were religious or spiritual, such as God's wrath, others were linked to animist beliefs and oral traditions such as a cow or zebu that had been buried and was moving its head beneath the ground. The existence of a submarine volcano or of secret oil drills were commonly believed. While the set of explanations have been in turn believed, researched, explained, mocked and ridiculed, all were taken under debate among citizens, including on the Facebook group. Further research would be needed to assess to what extent inhabitants of the island believed in one, or several, of these explanations. However, the way people exchanged their ideas of what caused the active earthquake swarm demonstrates a certain level of interest and illustrates the importance of constructing an explanatory frame of reference to citizens.

However, citizens not only had to find an explanation for the earthquakes, but also for the silence of the authorities and scientists. This led to an increase of mistrust toward the institutions that were seen as hiding the truth from the population. Joël, for instance, declared: "We need to know the truth. It's not possible... they're hiding the truth from us. Why? So, either we're just kids, underage who aren't told the truth... Or they're worried; the administration is worried and doesn't want to share the information. But it's no better. We don't know why they won't tell us!" This testimony is a typical example of the suspicious atmosphere in Mayotte during that time, which led to an increased mistrust toward institutions. Baptiste even noted that "At some point a theory was even explaining that the government created the earthquake swarm to prevent people from going on strike again, because they had done so during the previous 2 months" (Baptiste, 31 years old, journalist). This explanation falls under conspiracy theories, stimulated

\footnotetext{
${ }^{11}$ It is here to note that what was considered as a crazy theory revealed partly true as the earthquake swarm is indeed linked to a volcanic activity.
}

by emotional fatigue and mistrust toward the institutions. It appeared satisfactory to some members of the community as it provided an explanation both for the seismic phenomenon and for the information vacuum. Media may have also played a role. For instance, on January 17th 2019, an article in Mayotte la 1ère ${ }^{12}$, a local newspaper, reported that Paul Allen, an American billionaire, may have observed the birth of a volcano from his yacht "the Octopus" Beyond the facts, the author uses the lexical field of mystery, which may have reinforced already existing doubts and suspicion in the reader's mind.

In order to cope with the situation, reduce their anxiety and meet their needs for understanding the earthquakes (why, when, and how they happened), citizens turned to existing citizen seismology projects, and also created their own network.

\section{STTM, A SELF-STRUCTURED CITIZEN SEISMOLOGY COMMUNITY}

\section{Citizen Seismology for Citizens, by Citizens}

STTM ("Soutien Tremblement de Terre Mayotte"), standing for "Earthquake support Mayotte" is a Facebook group ${ }^{13}$ made up of more than 10,000 members. It was created a few days after the first earthquakes with the goal of gathering information about the situation.

Facebook is a major part of information and technology culture in Mayotte. Many interviewees describe how things can and must be done through this social media, such as booking an appointment with the aesthetician, checking a doctor's schedules or road traffic conditions. The road traffic condition page is indeed a popular one in Mayotte, gathering more than 49,000 users with on average of 230 posts per day according to Facebook data. After the first earthquake many started to discuss about it on the road traffic group. One of the group administrators thus decided to create a group dedicated to earthquakes for more consistency. According to some interviewees who know him, this man, who did not wish to be interviewed, has no specific knowledge about earthquakes. He just aimed at making users' navigation easier with an identified page for traffic and one for earthquakes.

The group was created by a citizen for citizens, in order for them to exchange what they know and feel about earthquakes. The group is public and anyone with a Facebook account can join it. It is moderated by a few volunteers who can decide of the rules of the group and exclude members who do not comply with them. Data is insufficient to get a precise overview of the sociological characteristic of the group and of these moderators. However, from what could be observed, messages were posted, commented and got reactions from both men and woman, in French and Shimaore.

After a felt earthquake citizens usually post messages to say where and when they felt it, and sometimes ask for complementary information such as magnitude (Figure 4, left). They also ask for and show emotional support, comment on each

\footnotetext{
${ }^{12}$ https://lalere.francetvinfo.fr/mayotte/naissance-volcan-au-large-mayotte670649.html

${ }^{13}$ https://www.facebook.com/groups/312080469323937/?ref=bookmarks
} 


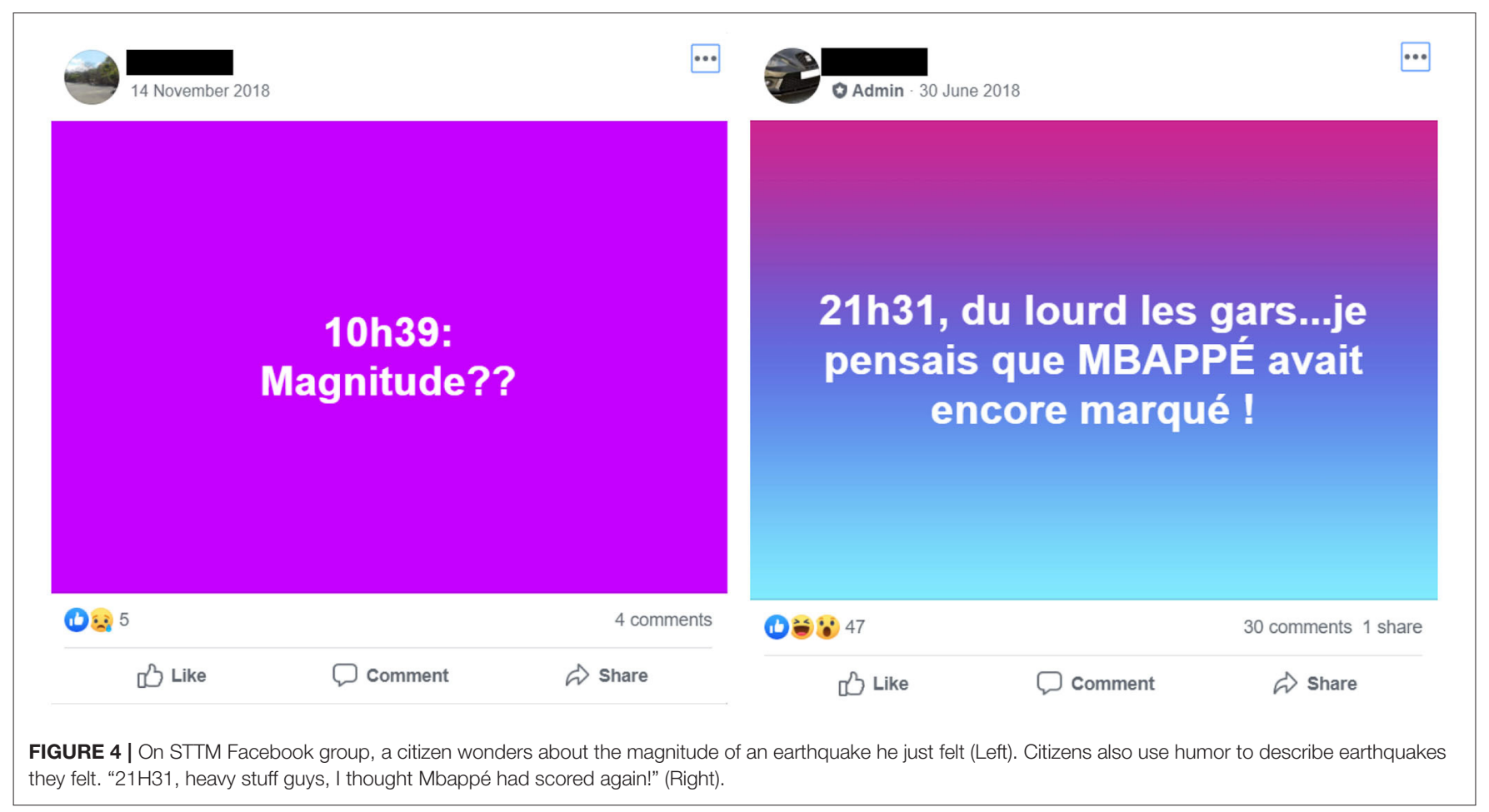

others' questions and posts. Some of them post in Shimaore. If, at first, they shared their anxiety about an unknown and unexplained phenomenon, the tone became lighter as they became partly used to it. Once members of the group became less anxious or frightened by the earthquakes, they also made great use of humor, in order to play down the situation. For instance, following an earthquake occurring during the football world cup (30th of June 2018), users compared earthquakes to shakings provoked by supporters after Mbappé, a French player, scored (Figure 4, right). As such STTM could be seen as a barometer for social emotions on the islands, relative to the seismic situation.

Most interviewees mentioned the STTM Facebook group spontaneously. One of the first functions of the group was to create a feeling of community, to be part of a shared experience. For Marie, "It was very reassuring to know that others had felt earthquakes in Mayotte, and that I was not crazy" (Marie, 26 years old, lawyer) and Lucile felt the same: "As soon as I feel an earthquake, I'm going on this page to check that it really was an earthquake. And I also check for damage. If something happened it's mentioned on this group, for sure. Everyone posts pictures of cracks or trees on the roads. And I can also check where it was felt, in which part of the island" (Lucile, 36 years old, teacher).

Many users in this Facebook group also discuss the potential causes of the earthquakes. Nadia for instance stated "I had basic knowledge of seismology; I knew what I learnt at school, but no more. When the earthquakes started, I made further research because there was no information. I wanted to know about the faults in the regions etc. I looked on the internet but also on this Facebook group, because there was a lot of information" (Nadia, 40 years old, nurse). Icham, imam on the island, also took part in the group to get more information and share his findings:
"I'm doing research... I'm not sure yet why there are all these earthquakes. Some will say it's God punishing us but I think it's more complicated than that. Maybe God is warning us about something; it still has to be studied. And that's why I'm in this group, to learn and share what I discovered" (Icham, 57 years old, imam).

Through this Facebook group, citizens thus launched a form of citizen seismology, as they shared knowledge and information about earthquakes they had felt as well as about the phenomenon. And they did so without the help from the seismologist community.

\section{Seismology Without Seismologists}

Initially, the group was not thought of as a citizen science tool, it was simply created to meet emotional and informational needs. No member of the scientific community per se took the lead of this group, and no seismic institution or authority member has officially contributed to its development.

Nevertheless, due to the length of the seismic crisis and to its initially unexplained cause, the group has taken a more and more scientific direction. Some members, those more interested in seismology or in this seismic phenomenon, took the lead and shared information in an understandable way for their fellow citizens. Information was related to felt earthquakes, as well as to seismology in general. Information about possible earthquake causes was shared and discussed. Basic seismological concepts such as magnitude and intensity were explained in a pedagogical way. Comparisons with other earthquake swarms were made. Historical data about Mayotte seismicity was documented along with information about seismological knowledge limits, and safety measures to take. Citizens thus took the lead on collecting 
data and reviewing the existing scientific literature which they had access to.

In addition, they also started to produce collated forms of knowledge, as one of the members started to list all felt earthquakes declared on the group and compare it to BRGM's seismic reports. Moreover, a few months after the beginning of the crisis, a user suggested launching a crowdfunding operation in order to equip the island with Raspberry Shakes. Raspberry Shakes are relatively affordable seismic sensors that can be installed easily in schools or in citizens' homes and that are used in many citizen seismology projects (Calais et al., 2018; Subedi et al., 2020). The crowdfunding project has not actually been implemented in Mayotte; however, it demonstrates a certain commitment level as well as an understanding of the lack of sensors and data issue.

Finally, in January 2019, a few members collected questions from the whole group and organized them in an open letter ${ }^{14}$ addressed to scientific institutions and authorities. During the first phase of the crisis that was observed, neither the BRGM nor the prefecture publicly engaged with the STTM page. Information was progressively made available on Prefecture's social media account and BRGM's website. Some active members of the group were invited to a meeting by the prefecture in October 2019 (a year and half after the beginning of the crisis) in order to discuss citizens' expectations, future research developments and measures to take.

The citizen seismology community was formed and selforganized through STTM Facebook group. Without direct interactions with seismologists, the active members in this group took a role in leading the discussion. Some members also relayed rumors, conspiracy theories and explanations that would not be considered as scientific, however, these were debated or fought against with humor. As a result, the general tone on the group became more and more scientific. It led to a perceived increase of global knowledge and interest for seismological matters among members of the group, from what could be observed. This could not be quantified and further study would be necessary.

Along with the STTM experience, another citizen response to the information vacuum was for them to turn to the LastQuake app to get timely information and leave their testimonies. However, seismic data was also lacking for EMSC's system to run efficiently and it had to be adapted.

\section{LASTQUAKE, A CITIZEN SCIENCE PROJECT EVOLVING WITH CITIZENS \\ An Innovative Citizen Seismology Project, Popular in Mayotte}

LastQuake is an innovative earthquake detection and information system developed by the EMSC. It is a multichannel system composed of a Twitter bot (@LastQuake), a mobile site and a free and ad-free mobile application. Its main goals are to provide information for the public as well as to collect data via

\footnotetext{
${ }^{14}$ Accessible at: https://www.change.org/p/m-le-pr\%C3\%A9fet-de-mayotteplus-d-informations-et-de-communication-sur-les-s\%C3\%A9ismes-\%C3\%A0mayotte
}

crowdsourcing. It detects peaks in web traffic and app launches that are characteristics of felt earthquakes. Indeed, when citizens feel an earthquake, they tend to look for information, quickly launching the LastQuake app, finding EMSC's website or tweeting about earthquakes. When launching the app, they are then asked to provide a testimony of how intensely they felt the event and can add a comment and/or a picture. This set of crowdsourced data is then merged with seismic data coming from partners' institutes. Originally, if after $15 \mathrm{~min}$ no seismic location had confirmed the crowdsourced detection, the event disappeared from the app as it was suspected of being a false detection (Bossu et al., 2018). Operating globally, it enables users to get timely information about felt earthquakes, being useful to eyewitnesses who want to get information or to share some (Figure 5), as well as to people interested in seismology or members of impacted communities located in other area. LastQuake also provides post-earthquake visual safety tips in order to contribute to risk reduction and help users adopting safe behaviors after an earthquake (Fallou et al., 2019). LastQuake's strategy of using visual content helps to address the challenges linked to its global distribution. Indeed, being used all over the world, the content must be as universally understandable as possible, regardless of language, cultural background, or literacy level.

LastQuake is a pioneering citizen seismology project that uses digital technologies, especially social media. As the system uses crowdsourcing to detect felt earthquakes, citizens are placed at the core of its system (Bossu et al., 2011). It was and continues to be developed by seismologists, however, in order to efficiently develop these citizen science tools, users feedback is crucial (Bossu et al., 2019).

Few weeks after the beginning of the seismic activity, more than $1 \%$ of the population in Mayotte had downloaded LastQuake, which is another sign of citizen's information needs ${ }^{15}$. Despite the popularity of the app on the island, users reported that not all needs were met, especially because some earthquakes that they had felt were not displayed in the app, or disappeared after they had left a testimony. In the comments section as well as on the app store and social media, users expressed ambivalent feelings toward the app. On the one hand it was helping them cope with the situation when information was available and they could share their experience, but on the other hand it often created frustration or suspicion when it wasn't. As with many other seismological institutes, EMSC received criticisms for the lack of information. EMSC thus launched a questionnaire in order to collect testimonies from users in Mayotte, to understand their specific information needs and improve LastQuake. Methodology for the survey is described in the Materials and Methodology section.

\section{Lessons Learned From Lastquake Users in Mayotte Information as a Necessity}

Through an open question about users' experience during the earthquakes, results confirmed that information can cure anxiety.

\footnotetext{
${ }^{15} 2,744$ people on $2018 / 06 / 18$.
} 

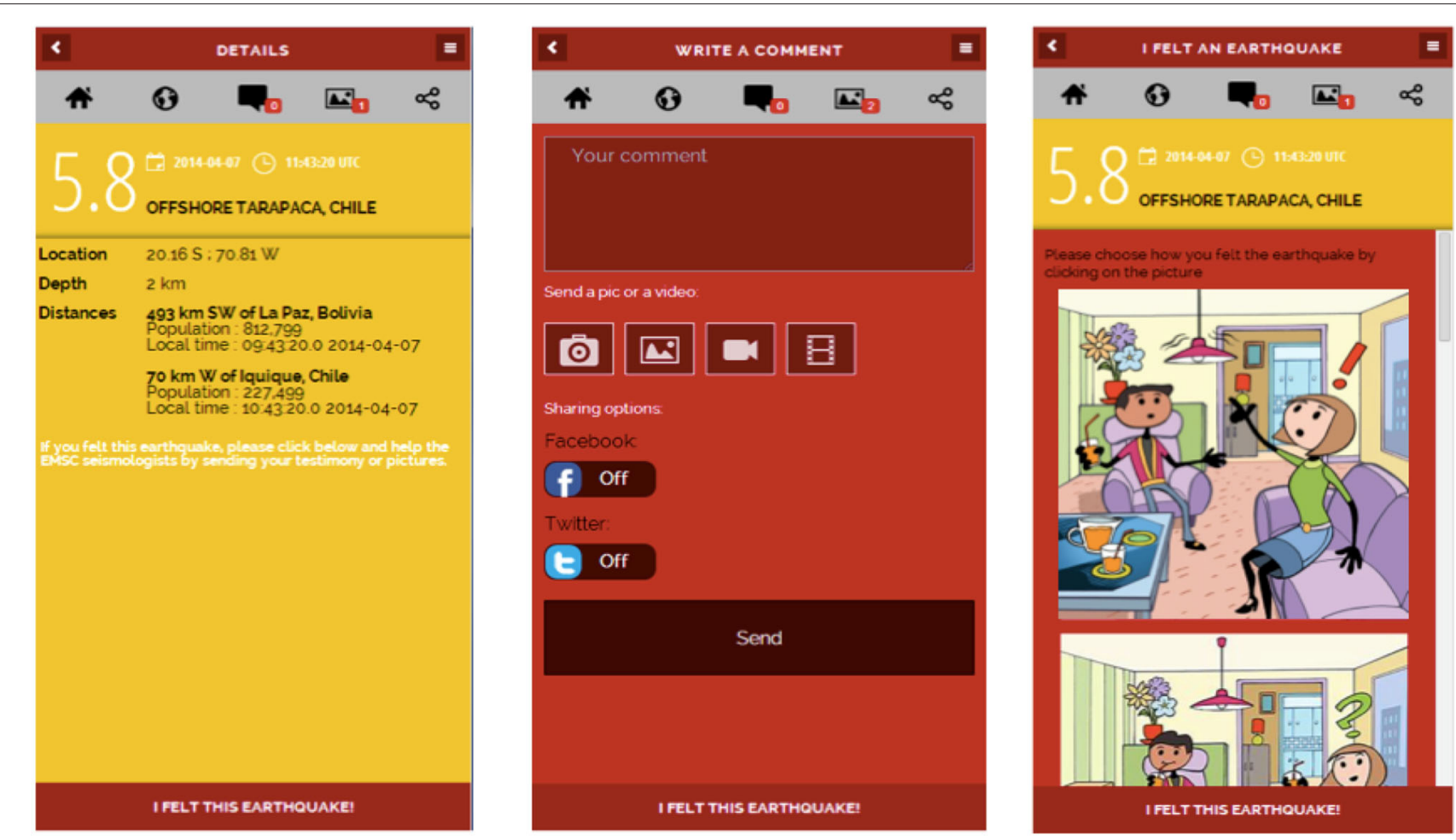

FIGURE 5 | LastQuake app enables users to get information about felt earthquakes (screenshot on the left), leave comments and pictures about earthquakes they felt (screenshot in the middle) and provide information about the intensity they experienced through a set of visuals (screenshot on the right).

Amongst all the answers, the following two illustrate well this phenomenon:

\begin{abstract}
"Anxiety and disturbed sleep for the first 15 days. Since then, I have been interested in the phenomenon scientifically and I have learned a lot about it. I have adapted to daily life; I now know how to react in the case of tremors."
\end{abstract}

"I lived for a week with fear in my stomach, but after I knew that you can't predict earthquakes and tsunamis, I started to get a little better but I will still be attentive."

However, information needs are of diverse types and are not always possible to meet.

\section{Missing Information and Mistrust}

Overall, $18 \%$ of the respondents declared to be "very satisfied" and $43 \%$ "satisfied" with the LastQuake app. This suggests room for improvements. Through an open question, users were encouraged to provide suggestions to make LastQuake more useful to them. Two hundred and ninety-seven respondents took this opportunity and made propositions. Among them, nearly one third left a comment related to the necessity to report all felt earthquakes in the app. Further, some mentioned their lack of understanding linked to the fact that earthquakes of small magnitudes were reported in other regions of the world (better equipped with sensors) but not in Mayotte.
$29 \%$ requested higher precision in the magnitude and location of earthquakes, and $15 \%$ to improve the rapidity of information sharing. Other popular suggestions also targeted the need for general information about the causes of the earthquakes (11\%), and the explanation of why seismic data was not available (8\%).

This is consistent with what was found in the semidirective interviews. For instance, Nadia stated that "The app is information served on a platter... But on the other hand, on the app I am not told that information will only be given from M4 onwards. And we constantly experienced ground shaking. We had about twenty earthquakes during the day and no information because it was below M4. So, for me the threshold to trigger the notifications was too high" (Nadia, 40 years old, nurse). Her statement actually reveals that she didn't understand that no information was provided not because of a threshold but because of a lack of seismic data. A similar frustration is presented by Nadine: "As soon as there was an earthquake, I would directly check my application, and then I was not happy because we had a lot of the earthquakes we felt that were not marked... whereas I had the M2.5 from Hawaii. I had felt more than M2.5 and I didn't care about the M2.5 in Hawaii. [...] You feel like you've been forgotten" (Nadine, 60 years old, teacher).

This added to the suspicion held by many users, as evidenced by some comments on the app. For instance, after a M4.6 event on 26th August 2018, among the 37 eyewitnesses comments, there are many questions regarding the absence of data for other felt earthquakes: "10 earthquakes felt today in Mayotte with an 
increasing intensity and duration... why don't you ${ }^{16}$ tell about them?", some even mention conspiracy suspicion: "Is it over? You no longer count the tremors in Mayotte? Government order?"17.

Comments on LastQuake along with questionnaire and interview results, reveal the frustration and mistrust created by the fact that some felt earthquakes were not displayed in the app, and by the lack of understanding of the way the system operated.

\section{The Ambivalent Relationship to Magnitude}

Both the questionnaire and interviews demonstrate that citizens attach great importance to magnitude even though they don't always understand it and sometimes confuse it with intensity ${ }^{18}$. This is consistent with Celsi et al. (2005) findings. In their research they demonstrate the cognitive anchoring process which leads people to compare their felt earthquake experience to the reported magnitude size of the earthquake, regardless of how far from the epicenter they were and other seismic parameters. This anchoring effect can be alleviated by scientific knowledge and understanding of seismicity (Celsi et al., 2005).

Providing the information of earthquake magnitude enables citizens to measure how much damage should be expected: "Magnitude is important... it tells me if I should worry or not. Under M5 I know it's ok, I don't have to be scared. But more than $5 \ldots$ it scares me. I remember well the M5.8 that occurred in May. I was alone at home and I was very very scared" stated Nadine. The same idea was expressed by Marie: "I'm very interested in magnitude, it's a point of reference. Now I know what a M4 can do in terms of damage. If I see a magnitude 6 or 7 on TV then I also know" (Marie, 26 years old, lawyer). However, her statement reflects a possible confusion between magnitude and intensity.

More interestingly, associating a magnitude to an earthquake was also found to be a way to legitimize the event, to give it a name and a certain form of existence. Providing a magnitude objectifies the earthquake. "When we get the magnitude, we know it's real, that someone in a lab has said "yes there was an earthquake" So yes, I'm really waiting for the magnitude. [...] And also, the magnitude it's nearly the name of the earthquake, when we discuss about it it's always "oh did you feel the 4.6 yesterday? And the 4.3?" We always use the magnitude, but sometime it varies so..." (Nadia, 40 years old, nurse).

Jean's view complements Nadia's as he stated that getting a magnitude not only enables confirmation of the fact that it was indeed an earthquake, but also confers a special status to those who felt it, which seemed important to him: "at least when you have the information [of magnitude], when they release it, it gives you the victim status. You know it was something, it really shook and you went through this. And you probably don't realize it, but it's important" (Jean, 60 years old, policeman). In other words, magnitude, being officially and publicly provided

\footnotetext{
$16 \ll$ you $\gg$ here targets EMSC.

${ }^{17}$ Comments available at: https://www.emsc-csem.org/Earthquake/Testimonies/ comments.php?id=715233

${ }^{18}$ Seismic magnitude scales are used to describe the energy released by an earthquake, while intensity represents the strength of the shaking at a given location. An earthquake has one magnitude, but impacts different locations with different intensities.
}

by an institution, certifies that an earthquake has been felt and, legitimizes the emotions experienced by eyewitnesses.

Citizens realized that a social validation of the seismic characteristic of what they felt was already an achievement and could alleviate anxiety. "Of course, magnitude is very important, but if there is at least the event in the app, it's already something. It would make me feel like we're not forgotten" (Lucile, 36 years old, teacher). This is supported by the fact that the Facebook group was created in order to share experience about felt earthquakes and get a confirmation that had also felt it. his is consistent with what we observed from STTM Facebook group that, the more citizens learn about the earthquake, the less anxious they feel. This suggests that with or without the complete seismic data, it is important for people to share and talk about their experience in an interactive platform (e.g., social media, app, and so on).

Overall, the results of the questionnaire and of the interviews suggested that citizens involved in the project needed to get information about earthquakes, even when it was incomplete, and also to understand how the detection system worked. This had two implications for LastQuake. First a new type of event with no associated magnitude or location was created, and secondly a communication effort was made to explain the system behind the app to citizens.

\section{LastQuake Improvements}

Following the questionnaire and interviews results which are essential tools used by EMSC to gain a return on experience and improve their tools, EMSC decided to create a new type of events in its app: incomplete events. Included in the LastQuake system at the beginning of January 2019, they are launched when a crowdsourced detection occurs and 8 felt reports, close in time and space, are left by eyewitnesses. This guarantees that a seismic event has indeed happened, even though it has not yet been associated with a magnitude or location. They turn into a regular event if/when they are finally associated with a magnitude and location thanks to official seismic data. During phase 4 of the case study (Figure 1), 28 events of this types appeared on the app, including 8 that were eventually completed with seismic location and magnitude.

These events have been designed in a way that underlines their specificity and their incomplete nature. They also follow the constraint that they must be understood at a global scale, regardless of cultural factors, language or literacy level. The term "earthquake" has been chosen from the beginning in order to stay simple and limit text in the app to keep it as universal as possible. However, if in most cases these events are indeed earthquakes, LastQuake can also detect felt shaking issued by sonic booms or meteors ${ }^{19}$. EMSC will then consider replacing "earthquake" by "shaking" in the event description, which would require translation in every language available in the app. They appear in brown in the app, whereas events with complete seismic information are represented in a range of colors from green to red depending on their intensity and impact. When associated with a magnitude and location they turn from brown

${ }^{19}$ See for instance: http://novilist.hr/Vijesti/Hrvatska/Kod-Ucke-u-atmosferiizgorio-meteor-Vidjela-se-jarka-svjetlost-i-trag-dima 

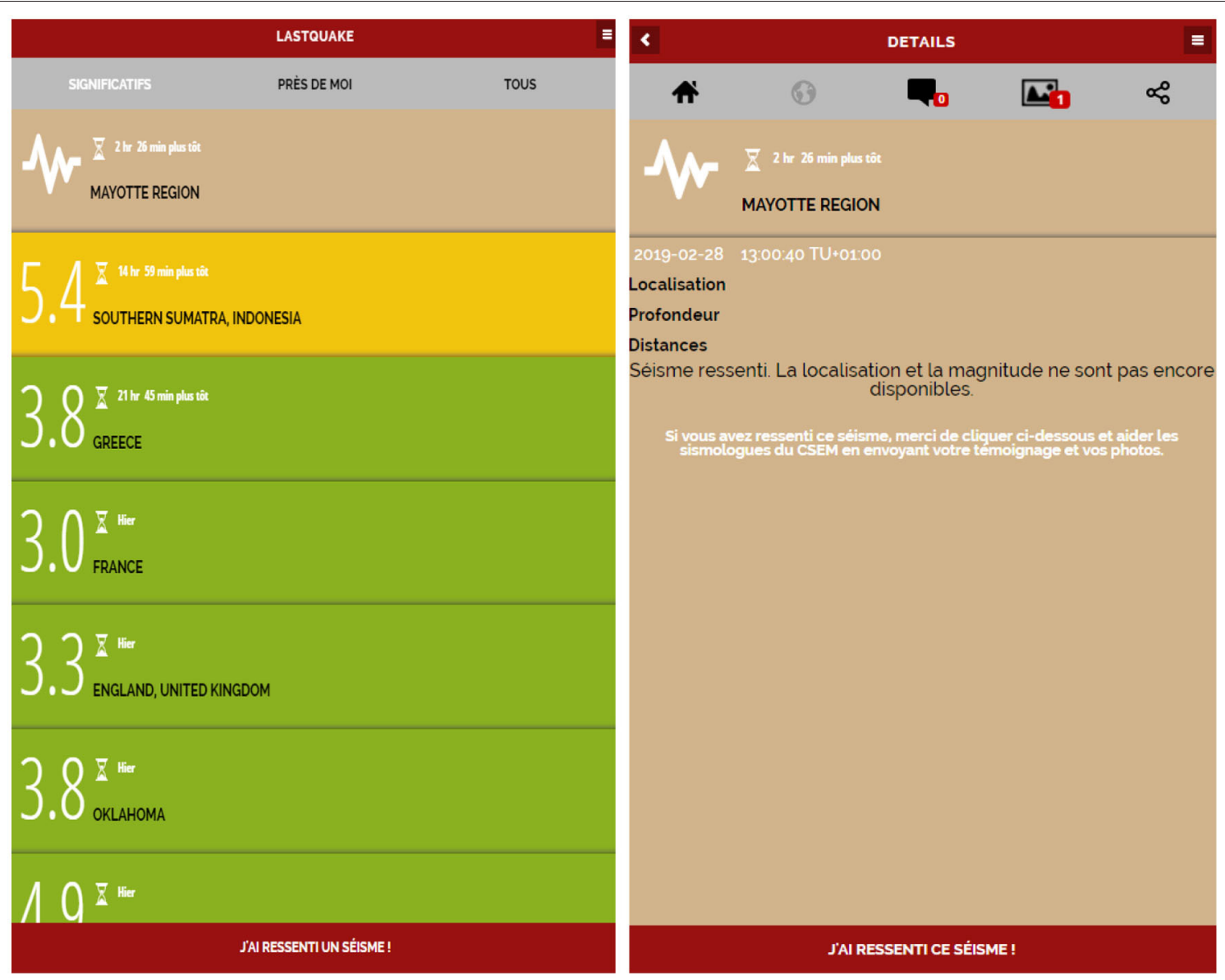

FIGURE 6 | A new type of event has been implemented in LastQuake (in brown). Though incomplete, the presence of some information has been found to be essential to users.

to their associated color. A seismic wave symbol is displayed instead of the magnitude to indicate the incomplete nature of the information (Figure 6).

When clicking on this new type of event, users access the event page, stating that the earthquake has been felt, but that magnitude and location are not available yet (Figure 6). This implies that information will be updated when and if possible. Textual contents were translated into all languages available in the app. As for any event, users can contribute and share their experience, stating how intensively they felt it. They are also encouraged to send photos and can access comments left by others, and a map of testimonies.

This new type of events was designed to respond to citizens' need for a validation that what they felt was really shaking and possibly an earthquake. This information, though incomplete (as no magnitude or location is associated) is essential for reducing anxiety levels. By providing all information available at a given time, assuming its incompleteness and publishing updates when available, EMSC guarantees a transparent information process. Based on comments collected through the app, social media and the application stores EMSC also observed that trust-based relationship with its users has been restored. It highlights that during a seismic crisis information needs must be hierarchized and prioritized. Even though magnitude and mapping effects were found to be important information, they appeared secondary compared to the confirmation of the seismic nature of what eyewitnesses had just experienced.

Additionally, EMSC's communication strategy has been revised in order to include materials explaining the nature of the detection system. Indeed, as LastQuake relies on the one hand on crowdsourcing and on the other hand on seismic data, citizens have to understand that not only are they a crucial part of the detection system, but also that no complete data can be published if sensors are lacking in a given region. This was made through a motion design video posted on social media and available on EMSC's website ${ }^{20}$. It is accessible easily on Twitter as it is the @LastQuake pinned post on Twitter. The video was designed in order to be universally understood by users, using no text or voice over.

\footnotetext{
${ }^{20}$ https://www.emsc-csem.org/service/application/
} 


\section{DISCUSSION}

\section{Citizen Seismology Without the Seismologists}

This Mayotte case-study shows that when information is not available to them, citizens will seize or create tools that meet their needs, and that they can do so without seismologists, as was the case for the Facebook group.

STTM, the Facebook group, was originally created, at least in part, in opposition to the seismologists' community who did not succeed in meeting nor managing their information needs. While it was not originally perceived as a citizen seismology tool, it slowly became one. The group, composed uniquely of citizens slowly became a full-fledged citizen-seismology group as they discussed not only their own earthquake experiences, but also causes and potential consequences of the swarm. Gathering more than 10,000 members, the group was not anecdotal and even took on a political dimension (in a broad sense) when they published an open-letter asking for political action and scientific responses. The number of members provides a certain form of legitimacy, even though expression on social media is still controversial and cannot be considered as representative. Their legitimacy was further raised by the prefecture who invited authoritative representatives of the Facebook group for a meeting to discuss information needs along with political and scientific actions.

STTM members' relation with scientists remained ambivalent. On the one hand the STTM members had strong expectations on scientists, and on the other hand they showed a lack of trust toward them. While citizens were debating on Facebook, scientists were gathering on Twitter, another social media, to discuss explanations for this seismic phenomenon (Lacassin et al., 2019). Both citizen and researcher communities were thus discussing about the same topic, but on different social media. Questions were formulated on Facebook by citizens while answers started to emerge on Twitter. This can be explained by technological culture as well as by socio-technical design of the platforms. Indeed, in Mayotte, Facebook is more commonly used by individuals for daily and personal uses, while Twitter has become a useful tool for researchers to exchange ideas, collaborate and share preliminary results.

On the whole, members of the groups appeared to have learnt about the situation and about seismology in general. However, citizen seismology initiatives like this one would benefit from the expertise of seismologists, especially to avoid mistrust, misinformation and conspiracy theories. Seismologists, providing information in an understandable way could contribute to the success of such citizen seismology enterprises, and thus to raise risk awareness, scientific knowledge and finally, to improve risk reduction. However, this represents a major challenge for all parties.

\section{Science Communication and Risk Communication for Citizen Seismology}

Citizen seismology lies between many disciplines that include not only seismology but also sociology to understand citizens' needs, science communication, and risk communication. Therefore, geoscientists need to investigate both fields when communicating with the public. Lamontagne and Flynn (2014) have already shown that in the aftermath of earthquakes, geoscientists have a key role to play in communication. They can contribute to reduce anxiety and promote recovery by sending messages that "provide a sense of safety, calming, self- and community efficacy, connectedness, and hope" (Lamontagne and Flynn, 2014). All these elements are important for citizens to feel reassured and cared for. However, information needs to be prioritized. Right after the earthquake, the main point of communication is to establish a public statement about the seismic event, and in a second time but in a timely manner, to provide seismic data such as magnitude, felt intensity, shaking map. This, along with post-earthquake safety tips will contribute to reduced anxiety. Furthermore, the Mayotte case demonstrates that during long-lasting seismic swarms, and when information is lacking, there is a need to communicate about the way seismology is done in order to limit the cognitive errors and unrealistic information expectations.

However, this requires that geoscientists are ready to communicate with the public. This does not only imply that they have special training but also that they identify themselves as responsible for communicating to the public. In Mayotte, in the first couple of days of the earthquake swarm, BRGM was expected to communicate with citizen and deliver more earthquake information. However, this institution is not always the official communicating actor for seismic hazards in France. Assessing public communication expectations and responsibilities beforehand is thus necessary, not only in terms of information to be provided but also of perceived legitimate actor to carry out the communication (Petersen et al., 2017).

\section{Understanding Information Needs and Cultural Background}

The example of both the STTM Facebook group and of LastQuake users' show that seismologists need to acknowledge citizens' questions and efforts in order to lead successful citizen seismology projects. Even though the public's expectations may not be realistic they can be managed. Seismologists could help leverage expectations by explaining the way they work, their constraints and what type of data they need. Re-asserting that, as of today, earthquakes cannot be predicted or that aftershocks will occur may be useful.

In order to communicate efficiently, information needs must be assessed locally as they vary depending on cultural factors as well as previous knowledge and experience. Research has found that the type of information, the legitimate and trusted actor, as well as the way the public want to receive it will vary depending on risk culture, technology culture, gender roles, age or religion for instance (Tagliacozzo and Magni, 2016; Appleby et al., 2019; Becker et al., 2019). This implies that scientific communication is an essential part of citizen science projects. As far as seismology is concerned this applies to both science communication and risk communication. Assessing needs and cultural context will also enable organizations to set up an inclusive communication (Canfield et al., 2020). 
Assessing information needs is also essential for designing efficient citizen science tools. Indeed, citizens will use technologies that meet their needs, especially in case of disaster (Appleby et al., 2019). This confirms that citizen seismology projects should set up ways to obtain user feedback on a regular basis and co-build the tools. Doing so enabled EMSC to understand that incomplete information was still valuable, and even essential to citizens. The simple fact of stating that an earthquake has been felt by other users can already contribute to reducing anxiety and avoiding suspicions.

\section{Avoiding Misinformation and Conspiracy Theories}

In the Mayotte case study, misinformation and conspiracy theories were partly fuelled by an information vacuum and increased by the pre-existing mistrust. Interviews revealed that citizens were seduced by conspiracy theories when they had to find an explanation for both the seismic events and the perceived silence of the scientific community and the authorities. Scientists thus have a key role to play, along with the authorities, in order to provide the reasons why the information is not available. Research takes time and citizens may not realize it, especially under high level of anxiety (Lamontagne and Flynn, 2014). Misinformation after a disaster or during a crisis is likely to spread and social media constitutes one of the ways (though not the only one) which it quickly expands (Keim and Noji, 2011; Rajdev and Lee, 2015). Thus, in order to limit the spread of misinformation, a proactive communication approach from scientists is required. This would help prevent rumors about earthquake prediction, anxiety and misinformation. However, science and risk communication require specific skills. Scientists can be trained to communicate with citizens better. This decision depends on many elements including personal proficiency and appetence, hazard context, as well as financial aspects. However, it must be addressed and scientists need to take part in the communication process.

However, the Mayotte case also reveals the importance of building a trust-based relationship beforehand, as part of a preparedness phase. This can include communicating about researchers' activities, or meeting the public for instance. No precursory sign could have warned the scientists in this case. However, given the duration of the situation, scientists from BRGM and other institutes have learnt to communicate more about their research activity on social media and in the press for instance. BRGM created a special page on their website ${ }^{9}$, and report research activity through press conferences and interviews. This seems to have contributed to an increase in trust among STTM, where members often share this content.

\section{Toward an Active Collaboration}

Overall, the Mayotte case study demonstrates the importance of an active collaboration between all actors, including citizens, seismologists, and authorities. Citizens have shown that they were willing to take an active role in order to meet their own information needs, especially when they perceive an information vacuum. Of course, not all of them have the same instruments in the project. Influential and motivated citizens stepped in to play an ambassador role for their community. This echoes the issue explored in the introduction. While more and more citizens get involved in citizen science projects, partly thanks to technology and social media, not all have the same level of engagement.

Collaboration between citizens and scientists is challenging as it requires common interests and mutual understanding. For instance, more interested and engaged citizens can be used as relays to spread information as was the case when a few members of the group were received by the prefecture and then passed the key messages on $\mathrm{STTM}^{21}$. These users were found to be not only seismology amateurs, but also influential on the group as many of others members are addressing directly to them. Efficient communication must then include a collaboration with interested and influential users (Kotras, 2012; Chong and Kim, 2016). The LastQuake example shows that integrating feedback is a key part of the process, in order to better meet citizen's information needs. Co-building citizen seismology tools is essential to ensure their use and efficiency (Fallou et al., 2019). This collaboration must also be done as a long-term process by taking advantage of teachable moments (Schwarz, 2004) which enables the community to remain active in between earthquakes. In Mayotte, citizens have already partly been more involved through an initiative from the prefecture who launched a process in August 2019 to have the volcano named by the pupils in Mayotte.

\section{CONCLUSION}

To date, earthquakes in Mayotte have fascinated seismologists around the world for nearly 2 years. Due to an initial lack of data and understanding of the phenomenon, information had been scarce at the beginning of the crisis. In this very specific seismic and cultural context, citizens, experiencing a high level of anxiety, expressed high information needs and expectations toward the scientific community. Facing an information vacuum, they seized the opportunity to use already existing citizen seismology tools such as LastQuake. They also launched their own network through Facebook. Due to a certain level of mistrust toward seismologists and communication failures, they created a community of citizen seismologists, without initially conceptualizing it as such. The reasons for the creation of such a group should call to mind seismologists as well as all citizen seismology actors, including authorities. It shows that citizen seismology projects must take cultural background into account as this shapes citizens' information needs in terms of type, form and media. Citizens in Mayotte have proven that they were willing to take on an active role on delivering correct and useful information associated with the earthquakes. It thus also demonstrates that when it comes to earthquakes, all citizens, not only amateurs may be involved in citizen science projects and that cooperation is essential to their success. Cocreating and co-developing citizen science tools will help to increase citizen knowledge about seismology, raise their interest in seismic technologies, raise risk awareness and contribute to

\footnotetext{
${ }^{21}$ https://lalere.francetvinfo.fr/mayotte/envoyes-du-groupe-facebook-sttmrecus-prefecture-737386.html
} 
risk reduction. Finally, the existence of this autonomous citizen initiative further proves that improving communication related to earthquakes requires actions from all actors. Citizens need to clearly express their information needs to the perceived legitimate institution(s), while this institution should consider and address this need in a comprehensive way. In cases involving a lack of data or explanations, communication must explain the reasons for this vacuum, in an educational and empathic way.

The Mayotte case is very unique as it is linked to an unusually long-lasting seismic activity, enabling the local community to develop and strengthen, becoming a key actor in crisis management. Despite the specificities of this case-study, it demonstrates that citizens, seismologist and authorities could already greatly benefit from collaboration. This should not remain wishful thinking, and represents a strong challenge as it requires that people with different cultural backgrounds and interests work together, with a longterm perspective. This is also part of the major challenge for earthquake early warning systems that are developing, which require an efficient communication system, and thus a strong collaboration between scientists, citizens and authorities (Allen et al., 2018). Technologies such as disaster apps and social media represent an astounding opportunity to build bridges between researchers and citizens and animate communities in between seismic sequences, making citizen science projects not only useful and accessible but attractive to all.

\section{DATA AVAILABILITY STATEMENT}

The datasets generated for this study are available on request to the corresponding author.

\section{REFERENCES}

Allen, R. M., Cochran, E. S., Huggins, T. J., Miles, S., and Otegui, D. (2018). Lessons from Mexico's earthquake early warning system. EOS 99. doi: 10.1029/2018EO105095

Appleby, S., Brockdorff, N., Fallou, L., and Bossu, R. (2019). Truth, trust, and civic duty: cultural factors in citizens' perceptions of mobile phone apps and social media in disasters. J. Contingencies Cris. Manag. 1, 1-13. doi: $10.1111 / 1468-5973.12282$

Aronova, E. (2017). Citizen seismology, stalinist science, and vladimir mannar's cold wars. Sci. Technol. Hum. Values 42, 226-256. doi: $10.1177 / 0162243916687643$

Barthès, C. (2003). L'Etat et le monde rural à Mayotte. Paris: Karthala.

Bastard, I., Cardon, D., Charbey, R., and Cointet, J. (2017). What do we do on facebook? Activity patterns and relational structures on a social network. Sociologie 1, 57-82. doi: 10.3917/socio.081. 0057

Becker, J. S., Potter, S. H., McBride, S. K., Wein, A., Doyle, E. E. H., and Paton, D. (2019). When the earth doesn't stop shaking: how experiences over time influenced information needs, communication, and interpretation of aftershock information during the canterbury earthquake sequence, New Zealand. Int. J. Disaster Risk Reduct. 34, 397-411. doi: 10.1016/j.ijdrr.2018.12.009

Bossu, R., Fallou, L., Julien-Laferriere, S., Landès, M., Roch, J., Roussel, F., et al. (2019). How to Improve Rapid Public Earthquake Information? Listen to

\section{ETHICS STATEMENT}

Ethical review and approval was not required for the study on human participants in accordance with the local legislation and institutional requirements. The participants provided their written informed consent to participate in this study.

\section{AUTHOR CONTRIBUTIONS}

LF led the research, conducted the interviews, did the social media observations, created the questionnaire, analyzed the results and wrote the manuscript. $\mathrm{LF}, \mathrm{RB}, \mathrm{ML}$, JR, and FR analyzed users' needs and contributed to designing the new type of events, implemented by FR in LastQuake system. ML provided data about seismic events and edited maps. RS and SJ-L have provided feedback during the discussions and writing process. All authors contributed to the article and approved the submitted version.

\section{FUNDING}

This article was partially funded by the European Union's Horizon 2020 research and innovation programme under grant agreement RISE No 821115 and grant agreement TurnKey No. 821046. Opinions expressed in this paper solely reflect the authors' view; the EU was not responsible for any use that may be made of information it contains.

\section{ACKNOWLEDGMENTS}

The authors thank interviewees and respondents to the questionnaire.

Eyewitnesses! EGU Blogpost. Available online at: https://blogs.egu.eu/divisions/ sm/2019/05/08/how-to-improve-rapid-public-earthquake-informationlisten-to-eyewitnesses/ (accessed July 16, 2020).

Bossu, R., Gilles, S., Mazet-Roux, G., and Roussel, F. (2011). "Citizen seismology: how to involve the public in earthquake response," in Comparative Emergency Management, eds D. M. Miller and J. Rivera (Boca Raton, FL), 235-257. doi: 10.1201/b10974-15

Bossu, R., Steed, R., Roussel, F., Landes, M., Fuenzalida, A., Matrullo, E., et al. (2018). App earthquake detection and automatic mapping of felt area. Seismol. Res. Lett. 90, 1-22. doi: 10.1785/0220180185

Boudon, R. (2001). La rationalité du religieux selon max weber. L'Année Sociol. 51, 9-50. doi: 10.3917/anso.011.0008

Calais, E., Etienne, G. P., Prépetit, C., Boisson, D., Courboulex, F., Deschamps, A., et al. (2018). Can a raspberry shake seismic network complement a national seismic network? A case study in Haiti. EarthArXiv Preprint. doi: 10.31223/osf.io/nyp7h

Canfield, K. N., Menezes, S., Matsuda, S. B., Moore, A., Austin, A. N. M., Dewsbury, B. M., et al. (2020). Science communication demands a critical approach that centers inclusion, equity, and intersectionality. Front. Commun. 5:2. doi: 10.3389/fcomm.2020.00002

Celsi, R., Wolfinbarger, M., and Wald, D. (2005). The effects of earthquake measurement concepts and magnitude anchoring on individuals' perceptions of earthquake risk. Earthq. Spectra 21, 987-1008. doi: 10.1193/1.2099047

Cesca, S., Letort, J., Razafindrakoto, H. N. T., Heimann, S., Rivalta, E., Isken, M. P., et al. (2020). Drainage of a deep magma reservoir near 
mayotte inferred from seismicity and deformation. Nat. Geosci. 13, 87-93. doi: 10.1038/s41561-019-0505-5

Chester, D. K., Duncan, A. M., and Dhanhani, H. A. G. (2013). Volcanic eruptions, earthquakes and Islam. Disaster Prev. Manag. Int. J. 22, 278-292. doi: 10.1108/DPM-04-2013-0079

Chong, M., and Kim, H. M. (2016). “\#Pray for paris with celebrities: the social role of influentials in a twitter network," in Bridging Asia and the World: Global Platform for Interface Between Marketing and Management (Hong Kong), 1688-1689. doi: 10.15444/GMC2016.12.01.05

Coen, D. R. (2012). Introduction: witness to disaster: comparative histories of earthquake science and response. Sci. Context 25, 1-15. doi: $10.1017 /$ S0269889711000275

Cornia, A., Dressel, K., and Pfeil, P. (2016). Risk cultures and dominant approaches towards disasters in seven European countries. J. Risk Res. 19, 288-304. doi: 10.1080/13669877.2014.961520

Dauphin, S., and Thibault, F. (2011). Mayotte : les spécificités du 101e départelent français. Rev. des Polit. Soc. Fam. 106, 94-97. doi: 10.3406/caf.2011.2656

Ditchfield, H., and Meredith, J. (2018). "Collecting qualitative data from facebook: approaches and methods," in The Sage Handbook of Qualitative Data Collection, ed U. Flick (Sage: London), 496-510. doi: 10.4135/9781526416070. $\mathrm{n} 32$

Edwards, R., and Holland, J. (2013). What is Qualitative Interviewing? London: A \& C Black.

Fallou, L., and Bossu, R. (2019). Taking into Account the Cultural Context to Improve Scientific Communication - Lessons Learned from Earthquakes in Mayotte. EGU blogpost. Available online at: https://blogs.egu.eu/divisions/sm/ 2019/03/08/taking-into-account-the-cultural-context-to-improve-scientificcommunication-lessons-learned-from-earthquakes-in-mayotte/ (accessed July 16, 2020).

Fallou, L., Petersen, L., Bossu, R., and Roussel, F. (2019). "Efficiently allocating safety tips after an earthquake - lessons learned from the smartphone application LastQuake," in Proceedings of the 16th ISCRAM Conference (Valencia), 263-275. Available online at: http://idl.iscram.org/files/laurefallou/ 2019/1943_LaureFallou_etal2019.pdf (accessed July 16, 2020).

Ferreira, T. (2019). "Two seismological approaches to the benavente earthquake (1909): from the network of citizens to the network of instruments," in Web of Knowledge: A Look into the Past, Embracing the Future (Évora).

Finazzi, F. (2016). The earthquake network project: toward a crowdsourced smartphone-based earthquake early warning system. Bull. Seismol. Soc. Am. 106, 1088-1999. doi: 10.1785/0120150354

Hachim, S. (2004). Catastrophes: Mayotte perd sa mémoire! Catastrophes naturelles et mémoire collective à Mayotte. Montpellier: Université Paul Valéry.

INSEE. (2017). INSEE Focus $n^{\circ} 105$, Montrouge. Available online at: https://insee. $\mathrm{fr} / \mathrm{fr} /$ statistiques/3286558\#consulter (accessed July 16, 2020).

International Seismological Centre (2020). Online Bulletin Board. Available online at: http://www.isc.ac.uk/iscbulletin/search/ (accessed July 16, 2020).

InterStats (2017). Insécurité et délinquance en 2016: premier bilan statistique. InterStats.

Keim, M. E., and Noji, E. (2011). Emergent use of social media: a new age of opportunity for disaster resilience. Am. J. Disaster Med. 6:47. doi: 10.5055/ajdm.2011.0044

Khan, A., Denton, P., and Bossu, R. (2018). Engaging citizen seismologists worldwide. Astron. Geophys. 59, 4.15-4.18. doi: 10.1093/astrogeo/aty190

Kotras, B. (2012). Des opinions qui (se) comptent. Influence, visibilité et hiérarchisation des opinions sur le web. Available online at: http:// socialmediaclub.fr/2013/12/smc-research-awards-les-laureats-du-concours/ (accessed July 16, 2020).

Lacassin, R., Devès, M., Hicks, S. P., Ampuero, J., Bossu, R., Bruhat, L., et al. (2019). Rapid collaborative knowledge building via twitter after significant geohazard events. Geosci. Commun. 3, 129-146. doi: 10.5194/gc-2019-23

Lambert, J. (1997). Contribution au relevé de la sismicité historique des îles de la Réunion, de Maurice et des Comores. BRGM R39736, 56. BRGM:Orléans.

Lamontagne, M., and Flynn, B. W. (2014). Communications in the aftermath of a major earthquake: bringing science to citizens to promote recovery. Seismol. Res. Lett. 85, 561-565. doi: 10.1785/0220130118
Lemoine, A., Bertil, D., Roullé, A., and Briole, P. (2019). The volcano tectonic crisis of 2018 east of Mayotte, Comoros Islands. EarthArXiv 1-33. Available online at: https://eartharxiv.org/d46xj?fbclid= IwAR2UugfcV1d25RrtCzNEgbvGuO_9YoDQS6b4BxIZNVe5juuL_X_4BOfSg0 (accessed July 16, 2020).

Liang, W. T., Chen, K. H., Wu, Y. F., Yen, E., and Chang, C. Y. (2016). Earthquake school in the cloud: citizen seismologists in Taiwan. Seismol. Res. Lett. 87, 177-185. doi: 10.1785/0220150061

Liang, W. T., Lee, J. C., Chen, K. H., and Hsiao, N. C. (2017). Citizen earthquake science in Taiwan: from science to Hazard mitigation. J. Disaster Res. 12, 1174-1181. doi: 10.20965/jdr.2017.p1174

Petersen, L., Fallou, L., and Serafinelli, E. (2017). "Public expectations of social media use by critical infrastructure operators in crisis communication," in Proceedings of the 14th ISCRAM Conference (Albi).

Rajdev, M., and Lee, K. (2015). "Fake and spam messages: detecting misinformation during natural disasters on social media," in Proceedings 2015 IEEE/WIC/ACM International Joint Conference on Web Intelligence and Intelligent Agent Technology, WI-IAT 2015 (Singapore), 17-20. doi: 10.1109/WI-IAT.2015.102

Saathoff, G., and Everly, G. (2002). Psychological challenges of bioterror: containing contagion. Int. J. Emerg. Ment. Heal. 4, 245-252.

Schwarz, S. (2004). Cyberseismology and teachable moments. Seismol. Res. Lett. 75, 749-750. doi: 10.1785/gssrl.75.6.749

Scolobig, A., Prior, T., Schröter, D., Jörin, J., and Patt, A. (2015). Towards people-centred approaches for effective disaster risk management: balancing rhetoric with reality. Int. J. Disaster Risk Reduct. 12, 202-212. doi: 10.1016/j.ijdrr.2015.01.006

Severn, R. T. (2012). Understanding earthquakes: from myth to science. Bull. Earthq. Eng. 10, 351-366. doi: 10.1007/s10518-011-9312-0

Sibley, C. G., and Bulbulia, J. (2012). Faith after an earthquake: a longitudinal study of religion and perceived health before and after the 2011 christchurch New Zealand earthquake. PLoS ONE 7:e49648. doi: 10.1371/journal.pone.0049648

Stephens, N. M., Fryberg, S. A., Markus, H. R., and Hamedani, M. Y. G. (2013). Who explains hurricane katrina and the chilean earthquake as an act of god? The experience of extreme hardship predicts religious meaning-making. J. Cross. Cult. Psychol. 44, 606-619. doi: 10.1177/002202211 2454330

Subedi, S., Hetényi, G., Denton, P., and Sauron, A. (2020). Seismology at school in Nepal: a Program for educational and citizen seismology through a low-cost seismic network. Front. Earth Sci. 8:73. doi: 10.3389/feart.2020.00073

Tagliacozzo, S., and Magni, M. (2016). Communicating with communities (CwC) during post-disaster reconstruction: an initial analysis. Nat. Hazards. 84, 2225-2242. doi: 10.1007/s11069-016-2550-3

Wald, D., Wald, D. J., Quitoriano, V., Worden, C. B., Hopper, M., and Dewey, J. W. (2012). USGS “Did you feel it?” Internet-based macroseismic intensity maps. Ann. Geophys. 54, 688-707. doi: 10.4401/ag-5354

Wein, A., Potter, S., Johal, S., Doyle, E., and Becker, J. (2016). Communicating with the public during an earthquake sequence: improving communication of geoscience by coordinating roles. Seismol. Res. Lett. 87, 112-118. doi: $10.1785 / 0220150113$

Wray, R., Rivers, J., Whitworth, A., and Clements, B. (2006). Public perceptions about trust in emergency risk communication: qualitative research findings. Int. J. Mass Emerg. Disasters 24, 45-75.

Conflict of Interest: The authors declare that the research was conducted in the absence of any commercial or financial relationships that could be construed as a potential conflict of interest.

Copyright (C) 2020 Fallou, Bossu, Landès, Roch, Roussel, Steed and Julien-Laferrière. This is an open-access article distributed under the terms of the Creative Commons Attribution License (CC BY). The use, distribution or reproduction in other forums is permitted, provided the original author(s) and the copyright owner(s) are credited and that the original publication in this journal is cited, in accordance with accepted academic practice. No use, distribution or reproduction is permitted which does not comply with these terms. 